Open Access

\title{
Impulse oscillometry identifies peripheral airway dysfunction in children with adenosine deaminase deficiency
}

\author{
Hirsh D. Komarow ${ }^{1 *}{ }^{*}$, Robert Sokolic ${ }^{2+}$, Michael S. Hershfield ${ }^{3}$, Donald B. Kohn ${ }^{4}$, Michael Young ${ }^{5}$,
} Dean D. Metcalfe ${ }^{1+}$ and Fabio Candotti ${ }^{2,6+}$

\begin{abstract}
Adenosine deaminase-deficient severe combined immunodeficiency (ADA-SCID) is characterized by impaired T-, B- and NK-cell function. Affected children, in addition to early onset of infections, manifest non-immunologic symptoms including pulmonary dysfunction likely attributable to elevated systemic adenosine levels. Lung disease assessment has primarily employed repetitive radiography and effort-dependent functional studies. Through impulse oscillometry (IOS), which is effort-independent, we prospectively obtained objective measures of lung dysfunction in 10 children with ADA-SCID. These results support the use of IOS in the identification and monitoring of lung function abnormalities in children with primary immunodeficiencies.
\end{abstract}

Keywords: Adenosine deaminase deficiency, SCID, Children, Pulmonary dysfunction, Impulse oscillometry, Spirometry

\section{Background}

Children with primary immunodeficiency diseases (PIDs) often suffer from severe and life-threatening illnesses. Adenosine deaminase (ADA) deficiency is among the most severe forms of PIDs, leading to severe combined immunodeficiency (SCID) and susceptibility to severe and recurrent opportunistic infections. In addition, the ubiquitous expression of ADA confers additional clinical phenotypes to patients affected with ADA-SCID that include noninfectious abnormalities of the lung that are incompletely characterized $[1,2]$. Assessment of lung disease in children may employ X-ray and conventional tomography imaging, while lung function is usually evaluated using spirometry, which is effort-dependent and thus difficult to perform in younger patients. Impulse oscillometry (IOS) has been suggested as an alternative technique to assess lung function with a

\footnotetext{
* Correspondence: komarowh@niaid.nih.gov

${ }^{\dagger}$ Equal contributors

'Laboratory of Allergic Diseases, National Institute of Allergy and Infectious Diseases, National Institutes of Health, NIH/NIAID/LAD/Bldg. 10, Room 1C129A1, 10 Center Drive, Bethesda, MD 20892-1960, USA

Full list of author information is available at the end of the article
}

particular application to younger children and others unable to perform spirometry [3-5]. IOS is best understood as a technique that generates small pressure oscillations that are applied at the mouth and transmitted into the lungs, which in turn enables the measurement of resistance and reactance to the impedance of the respiratory system during spontaneous quiet breathing, and therefore provides an indirect quantification of lung function.

\section{Findings}

Subject characteristics

We assessed lung function in 10 children (3-18 years of age) with ADA-SCID by IOS and spirometry following informed consent. Seven patients were on treatment with PEG-ADA and 3 with gene therapy. Six patients had undergone CT imaging of their lungs and displayed: diffuse ground glass opacities $(n=3)$, parenchymal cysts $(n=2)$, mosaic attenuation $(n=4)$, bronchiectasis $(n=1)$, and nodules $(n=1)$. All patients could perform IOS while only 5 patients were able to complete spirometry (Table 1). In addition, 82 control 
Table 1 Patient characteristics and pulmonary imaging and function testing

\begin{tabular}{lllllll}
\hline UPN & Age (years) & Gender & Ethnicity $^{\text {a }}$ & Treatment $^{\text {b }}$ & CT & Spirometry \\
\hline 1-ADA26 & 3 & F & C & 1 & ND & + \\
2-ADA41 & 5 & F & C & 2 & ND & + \\
3-ADA14 & 8 & F & C & 2 & Normal & + \\
4-ADA16 & 9 & M & H & 1 & dGGO, MA, B & - \\
5-ADA18 & 10 & F & A & 2 & ND & + \\
6-ADA5 & 12 & M & AA & 1 & MA & + \\
7-ADA46 & 14 & F & C & 2 & dGGO, PC, MA, N & - \\
8-ADA17 & 16 & F & AA & 2 & MA & - \\
9-ADA3 & 17 & M & C & 2 & dGGO, PC & + \\
10-ADA47 & 18 & M & AA & 2 & ND & + \\
\hline
\end{tabular}

${ }^{\mathrm{a}} \mathrm{C}=$ Caucasian, $\mathrm{H}=$ Hispanic, $\mathrm{A}=\mathrm{Asian}, \mathrm{AA}=$ African American

$\mathrm{b}_{1}=$ Gene Therapy; 2 = ADA conjugated with polyethylene glycol (PEG-ADA)

CT findings: ND CT not performed, $d G G O$ diffuse ground glass opacities, $P C$ parenchymal Cysts, MA Mosaic attenuation, $B$ Bronchiectasis, $N$ Nodules

+ Indicates successful completion of Spirometry and/or IOS

subjects of ages 4-18 were evaluated following informed consent. Details regarding methodology, demographics, disease presentation, ADA activity, pulmonary and immune status are shown in Additional file 1: Table S1.

\section{Pulmonary function measurements}

Patient characteristics did not differ significantly when subdividing the entire cohort $(n=10)$ into patients that could $(n=5)$ and could not $(n=5)$ perform spirometry (due to intellectual or physical disability) and in comparison to age matched healthy controls $(n=82$, Table 2$)$. The mean baseline measurements of patients with ADA-SCID were within the normal range for spirometry and IOS (Table 3). With the exception of a higher expiratory peak flow (PEF), on average, ADA-SCID patients showed spirometry results similar to healthy controls (Table 3). IOS testing, however, revealed that the ADA-SCID patient cohort presented significant increases in baseline percent-predicted values for resistance at $5 \mathrm{~Hz}$ (R5, $p=0.032$; Student $t$-test), and $10 \mathrm{~Hz}$ (R10, $p=0.044$; Student $t$-test). Peripheral airway reactance was also significantly increased as indicated by higher $\mathrm{X}$ values at $5 \mathrm{~Hz}$ (X5, $p=0.001$, data summarized in Fig. 1a) and change in X5 from reference (X5ref-X5, $p=0.041$; Table 3, italicized values). Although, as a group, the R5-R20(\%) of ADA-SCID patients did not differ significantly from control subjects, 4 patients had abnormal values (>35\%). Thus, patients with ADA-SCID displayed measurable defects in peripheral airway that was detected by IOS and not spirometry. A more detailed analysis focusing on individual patients revealed that 2 out of 5 patients who completed spirometry (based on FEV1) and 7 out of 10 patients who underwent IOS (based on R5, R5-R20\% and X5ref-X5) had abnormal baseline pulmonary function (Additional file 1: Table S2).

After bronchodilator administration, the mean response in ADA-SCID patients was within the normal range for both spirometry and IOS, except for an improved mean $\Delta \mathrm{R} 10$ of $-15.4 \%$, indicating borderline airways hyperreactivity (cutoff $-15 \%$, Table 4, Fig. 1b). An individual analysis of the 4 patients that underwent post-bronchodilator spirometry revealed that none of the patients displayed reversibility (FEV1 cutoff, $12 \%$ change). However, IOS testing was able to detect

Table 2 Pulmonary function testing in patients vs. controls

\begin{tabular}{|c|c|c|c|c|c|}
\hline Characteristics & $\operatorname{IOS}(n=10)$ & Spirometry able $(n=5)$ & IOS and not Spirometry $(n=5)$ & Controls $(n=82)$ & ${ }^{\mathrm{a}} P$ value ( $t$-test) \\
\hline Age mean (SD) & $11.2(5.1)$ & $13.0(4.6)$ & $9.4(5.3)$ & $9.22(3.21)$ & 0.090 \\
\hline Female Gender, n (\%) & $6(60)$ & $2(40)$ & $4(80)$ & $34(41)$ & 0.332 \\
\hline Height (cm) & $135.9(25.7)$ & $146.3(27.2)$ & $125.5(21.9)$ & $136.22(17.16)$ & 0.957 \\
\hline Weight (kg) & $44.3(26.8)$ & $54.6(30.5)$ & 33.9 (20.4) & 39.64 (28.68) & 0.630 \\
\hline
\end{tabular}

${ }^{\mathrm{a}}$ comparison of IOS $(n=10)$ to Controls 
Table 3 Baseline results in patients vs. controls

\begin{tabular}{|c|c|c|c|c|c|c|}
\hline \\
\hline \multicolumn{7}{|l|}{ Baseline Measurements } \\
\hline Spirometry & Patients $n=5$ & Controls $n=82$ & & Patients $n=5$ & Controls $n=82$ & \\
\hline FEV1 (L) & $2.2(1.0)$ & $1.85(0.7)$ & 0.354 & $86.0(8.2)$ & $90.8(22.4)$ & 0.636 \\
\hline FVC $(L)$ & $2.5(1.2)$ & $2.28(0.9)$ & 0.576 & 89.8 (11.8) & $100.7(17.6)$ & 0.178 \\
\hline FEV1/FVC (\%) & $86.8(3.4)$ & $82.0(9.9)$ & 0.282 & & & \\
\hline PEF (L/sec) & $6.2(3.6)$ & $4.0(1.6)$ & 0.007 & $104.8(25.5)$ & $95.1(25.8)$ & 0.418 \\
\hline Impulse oscillometry & Patients $n=10$ & Controls $n=82$ & & Patients $n=10$ & Controls $n=82$ & \\
\hline $\mathrm{R} 5\left(\mathrm{cmH}_{2} \mathrm{O} / \mathrm{L} / \mathrm{sec}\right)$ & $8.4(3.3)$ & $7.8(2.3)$ & 0.488 & $122.3(33.3)$ & $103.4(24.7)$ & 0.032 \\
\hline $\mathrm{R} 10\left(\mathrm{cmH}_{2} \mathrm{O} / \mathrm{L} / \mathrm{sec}\right)$ & $6.9(2.5)$ & $6.4(1.7)$ & 0.451 & $112.3(33.9)$ & $95.9(22.4)$ & 0.044 \\
\hline $\mathrm{R} 20\left(\mathrm{cmH}_{2} \mathrm{O} / \mathrm{L} / \mathrm{sec}\right)$ & $5.7(1.9)$ & $5.4(1.3)$ & 0.592 & $98.0(27.0)$ & $93.8(22.5)$ & 0.592 \\
\hline R5-R20 $(\%)^{\Delta}$ & $30.6(9.4)$ & $29.6(11.0)$ & 0.780 & & & \\
\hline X5 ( $\left.\mathrm{cmH}_{2} \mathrm{O} / \mathrm{L} / \mathrm{sec}\right)$ & $-3.6(1.8)$ & $-3.0(1.3)$ & 0.231 & $182(78.7)$ & $118.7(50)$ & 0.001 \\
\hline $\mathrm{AX}\left(\mathrm{cmH}_{2} \mathrm{O} / \mathrm{L}\right)$ & $27.5(21.6)$ & $22.4(14.6)$ & 0.323 & & & \\
\hline Fres $\mathrm{Hz}$ & $22.2(6.3)$ & $20.5(4.4)$ & 0.280 & & & \\
\hline X5ref-X5 (cmH $\left.{ }_{2} \mathrm{O} / \mathrm{L} / \mathrm{sec}\right)$ & $1.3(1.2)$ & $0.35(1.3)$ & 0.041 & & & \\
\hline
\end{tabular}

${ }^{\mathrm{a}}$ Normal cut-off: Spirometry $>80 \%$ Reference; IOS: R5, R10, R20, $<140 \%$ Ref, X5ref-X5 $<1.5 \mathrm{~cm} \mathrm{H}, 0 / \mathrm{L} / \mathrm{sec},{ }^{\Delta} \mathrm{R} 5-\mathrm{R} 20<35 \%$

significant reversible obstruction in half of the cohort, including 2 of the 4 patients who did not show reversibility by spirometry (Additional file 1: Table S2).

Thus, in a cohort of 10 children with ADA-SCID, IOS was easily employed to assess dynamic lung function; while half of the patients could not complete spirometry testing. Baseline abnormality of pulmonary resistance (R) and reactance $(\mathrm{X})$ was detected in the majority of ADA-SCID patients $(70 \%)$ using IOS. Undiagnosed reversible airway disease was revealed in half of the patients and only when using IOS. Also, in comparison to a pediatric control group of 82 patients, statistically significant abnormalities of peripheral airways were detected as indicated by measurement of airway resistance and reactance at lower frequencies (R5, R10, and X5).

\section{Discussion}

Adenosine deaminase deficiency causes bronchial inflammation, pulmonary fibrosis and alveolar enlargements in Ada knockout mice [6-8]. Similarly, noninfectious lung abnormalities are emerging as frequent complications in patients with ADA-SCID. In prior reports, these abnormalities appeared to resolve upon enzyme replacement or transplantation $[1,2]$. However, our results provide clinical evidence of continuing peripheral airway dysfunction in a significant fraction of patients receiving treatment resulting in sufficient correction of their immune function. These findings suggest that current therapeutic approaches such as ERT and gene therapy may be insufficient in preventing or controlling lung complications in ADA-SCID. Whether this is also the case of hematopoietic stem cell transplantation [9] remains to be investigated. Our IOS data indicates clinical evidence of continuing peripheral airway dysfunction in a significant fraction of patients that received treatment resulting in improvement of their immune function. The majority of patients with persistent lung disease (pneumonias, bronchiectasis) had abnormal findings on IOS. These observations appear to be independent of age and dAXP levels of diagnosis, and type of therapy employed (enzyme replacement or gene therapy). There were no correlations between the presence of lung abnormalities and demographics, therapeutic, and immunological parameters, however, we recognize that the small number of patients studied may have limited the ability to detect the effects of such variables. However, we believe it is important to caution care providers that ADA-SCID patients may benefit from therapies that target peripheral airway inflammation like inhaled corticosteroids and leukotriene inhibitors [10]. The long-term clinical significance in lung abnormalities in ADA-SCID patients is unknown, but our observations support the use of IOS for the identification and monitoring of this complication in children with this and other primary immunodeficiencies.

\section{Additional file}

Additional file 1: Online Supplementary Material. Table S1. ADASCID patient cohort characteristics. Table S2. Baseline and Reversibility. (DOCX $75 \mathrm{~kb})$ 


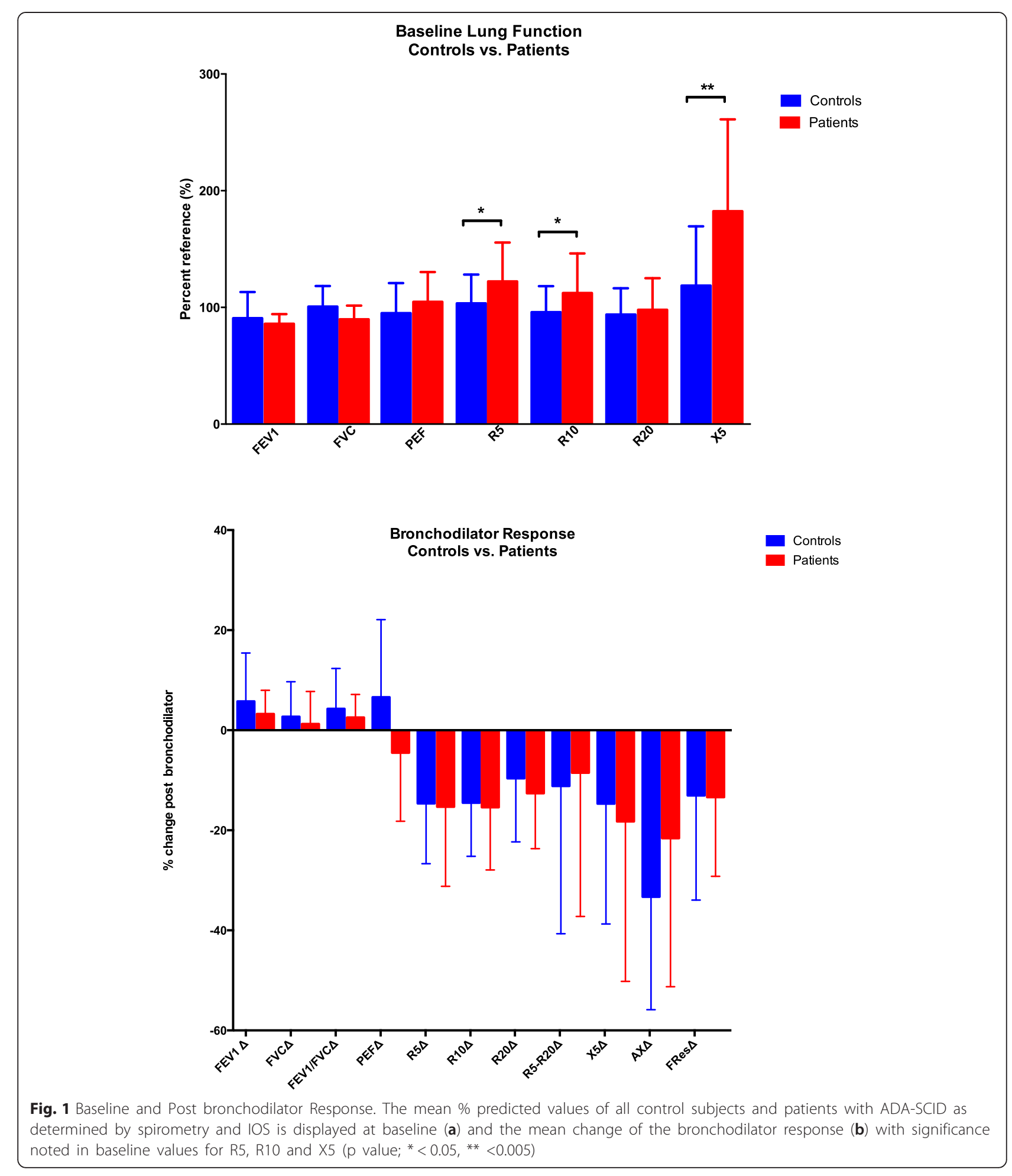


Table 4 Bronchodilator response in patients vs. controls

\begin{tabular}{llll}
\hline $\begin{array}{l}\text { Bronchodilator } \\
\text { response }\end{array}$ & & \\
& $\begin{array}{l}\text { Mean \% change } \\
\text { (SD) }\end{array}$ & & $\begin{array}{l}\text { P value } \\
\text { (T-test) }\end{array}$ \\
\hline Spirometry & Patients $n=4$ & Controls $n=82$ & \\
$\Delta \mathrm{FEV} 1$ & $3.3(4.7)$ & $5.5(9.7)$ & 0.607 \\
$\Delta \mathrm{FVC}$ & $1.3(6.5)$ & $2.7(7.0)$ & 0.341 \\
$\Delta \mathrm{FEV} 1 / \mathrm{FVC}$ & $2.5(4.6)$ & $4.3(8.1)$ & 0.672 \\
$\Delta \mathrm{PEF}$ & $-4.5(13.7)$ & $6.5(15.5)$ & 0.164 \\
Impulse oscillometry & Patients $n=10$ & Controls $n=82$ & \\
$\Delta \mathrm{R} 5$ & $-15.3(15.9)$ & $-14.6(12.0)$ & 0.438 \\
$\Delta \mathrm{R} 10$ & $-15.4(12.5)$ & $-14.5(10.7)$ & 0.809 \\
$\Delta \mathrm{R} 20$ & $-12.6(11.1)$ & $-9.6(12.7)$ & 0.483 \\
$\Delta \mathrm{R} 5-\mathrm{R} 20$ & $-8.5(28.7)$ & $-11.7(29.8)$ & 0.745 \\
$\Delta \mathrm{XX} 5$ & $-18.2(31.9)$ & $-14.7(24.0)$ & 0.673 \\
$\Delta \mathrm{AX}$ & $-21.6(29.7)$ & $-33.3(22.6)$ & 0.139 \\
$\Delta$ Fres & $-13.4(15.8)$ & $-13.1(20.9)$ & 0.961 \\
\hline
\end{tabular}

${ }^{a}$ Airway reversibility was considered evident when there was an improvement in any of the following bronchodilator parameters : $\triangle \mathrm{R} 5 \geq-20 \%, \Delta \mathrm{R} 10 \geq-15 \%$, $\Delta \mathrm{R} 20 \geq-20 \%, \Delta \mathrm{AX} \geq-45 \%$, and $\Delta \mathrm{Fres} \geq-25 \%$. By design, the percent improvement (reversibility) is displayed as a negative number because it indicates a magnitude decrease in resistance or reactance

\section{Abbreviations}

ADA-SCID: Adenosine deaminase deficient severe combined immunodeficiency; IOS: Impulse Oscillometry; FVL: Flow-volume loop; PFTs: Pulmonary function tests; ERS/ATS: European respiratory society/American thoracic society; Z: Impedance; R: Resistance; X: Reactance; Hz: Hertz.

\section{Competing interests}

The authors declare that they have no competing interests.

This work was supported by the Division of Intramural Research, NIAID and NHGRI, NIH and by an UNIL-CHUV grant (CGRB 29583 to F.C.). Support by M.Y. for this project was funded in whole or in part with federal funds from the National Cancer Institute, National Institutes of Health, under Contract No. HHSN261200800001E and [in part] by the National Institute of Allergy and Infectious Diseases. The content of this publication does not necessarily reflect the views or policies of the Department of Health and Human Services, nor does mention of trade names, commercial products, or organizations imply endorsement by the U.S. Government. Authors state no conflict of interest.

\section{Authors' contributions}

Conception or design: HK, RS, DM, FC; Acquisition, analysis, or interpretation: $H K, R S, M Y, D K, M H, D M, F C$; Drafting for important intellectual content: HK, RS, MY, DM, FC; Final approval of the version to be published: HK, RS, DK, MH, MY, DM, FC; Agreement to be accountable for all aspects of the work in ensuring accuracy or integrity: HK, RS, DK, MH, MY, DM, FC. All authors read and approved the final manuscript.

\section{Acknowledgements}

Appreciate Hans-Juergen Smith providing background testing reference information and Avanti Desai for assisting with statistical analysis and figure display.

\section{Author details}

${ }^{1}$ Laboratory of Allergic Diseases, National Institute of Allergy and Infectious Diseases, National Institutes of Health, NIH/NIAID/LAD/BIdg. 10, Room 1C129A1, 10 Center Drive, Bethesda, MD 20892-1960, USA. ${ }^{2}$ National Human Genome Research Institute, National Institutes of Health, Bethesda, MD 20892, USA. ${ }^{3}$ Department of Biochemistry, Duke University School of Medicine, Durham, NC, USA. ${ }^{4}$ Department of Microbiology, Immunology and Molecular Genetics, University of California Los Angeles, David Geffen School of Medicine, Los Angeles, CA, USA. ${ }^{5}$ Clinical Research Directorate/Clinical Monitoring Research Program, Leidos Biomedical Research, Inc., Frederick National Laboratory for Clinical Research, Frederick, MD 21702, USA. ${ }^{6}$ Division of Immunology and Allergy, University Hospital of Lausanne, $\mathrm{CH}-1101$ Lausanne, Switzerland.

Received: 21 August 2015 Accepted: 12 November 2015 Published online: 18 December 2015

\section{References}

1. Grunebaum E, Cutz E, Roifman CM. Pulmonary alveolar proteinosis in patients with adenosine deaminase deficiency. J Allergy Clin Immunol. 2012;129(6):1588-93.

2. Booth C, Algar VE, Xu-Bayford J, Fairbanks L, Owens C, Gaspar HB. Non-infectious lung disease in patients with adenosine deaminase deficient severe combined immunodeficiency. J Clin Immunol. 2012;32(3):449-53.

3. Bickel S, Popler J, Lesnick B, Eid N. Impulse oscillometry: interpretation and practical applications. Chest. 2014;146(3):841-7.

4. Komarow HD, Myles IA, Uzzaman A, Metcalfe DD. Impulse oscillometry in the evaluation of diseases of the airways in children. Ann Allergy Asthma Immunol. 2011;106(3):191-9.

5. Beraldo PS, Mateus SR, Araujo LM, Horan TA. Forced oscillation technique to detect and monitor tracheal stenosis in a tetraplegic patient. Spinal Cord. 2000;38(7):445-7.

6. Blackburn MR, Volmer JB, Thrasher JL, Zhong H, Crosby JR, Lee JJ, et al. Metabolic consequences of adenosine deaminase deficiency in mice are associated with defects in alveogenesis, pulmonary inflammation, and airway obstruction. J Experimental Med. 2000;192(2):159-70.

7. Dhanju R, Min W, Ackerley C, Cimpean L, Palaniyar N, Roifman CM, et al. Pulmonary alveolar proteinosis in adenosine deaminase-deficient mice. J Allergy Clin Immunol. 2014;133(5):1467-71. 71 e1-4.

8. Chunn JL, Molina JG, Mi T, Xia Y, Kellems RE, Blackburn MR. Adenosinedependent pulmonary fibrosis in adenosine deaminase-deficient mice. J Immunol. 2005;175(3):1937-46.

9. Hassan A, Booth C, Brightwell A, Allwood Z, Veys P, Rao K, et al. Outcome of hematopoietic stem cell transplantation for adenosine deaminase-deficient severe combined immunodeficiency. Blood. 2012;120(17):3615-24. quiz 26.

10. Usmani OS. Small-airway disease in asthma: pharmacological considerations. Curr Opin Pulm Med. 2015;21(1):55-67.

\section{Submit your next manuscript to BioMed Central and take full advantage of:}

- Convenient online submission

- Thorough peer review

- No space constraints or color figure charges

- Immediate publication on acceptance

- Inclusion in PubMed, CAS, Scopus and Google Scholar

- Research which is freely available for redistribution

Submit your manuscript at www.biomedcentral.com/submit 